\title{
Institutional Governance, Education and Growth
}

\author{
Mohamed Bouzahzah ${ }^{1,2^{*}}$, Simplice A. Asongu, ${ }^{1,3}$, Mohamed Jellal1 \\ ${ }^{1}$ Al Makrizi Institut d'Economie, Rabat, Morocco \\ ${ }^{2}$ FSJES Salé, Mohammed V University, Rabat, Morocco \\ ${ }^{3}$ African Governance and Development Institute, Yaoundé, Cameroon \\ Email: *mobouzahzah@gmail.com
}

Received 15 January 2016; accepted 28 March 2016; published 31 March 2016

Copyright (C) 2016 by authors and Scientific Research Publishing Inc.

This work is licensed under the Creative Commons Attribution International License (CC BY). http://creativecommons.org/licenses/by/4.0/

(c) (i) Open Access

\section{Abstract}

This study articulates the interaction among institutional governance, education and economic growth. Given the current pursuit of education policy reforms and knowledge economy around the world, it is of policy relevance to theoretically analyze the main mechanisms by which the macroeconomic impact of education on growth (and economic development) occurs. Our theoretical model demonstrates how incentives offered by the government affect human capital accumulation which ultimately engenders positive economic development externalities. We articulate two main channels through which education affects economic growth. The first channel highlights direct positive effect of educational quality on the incentive to accumulate human capital by individuals, which makes them more productive. The second channel appears in the explicit function of the economic growth rate. As a policy implication, we have shown that the growth rate depends on the rate of return on human capital or that this rate of return itself depends on the quality of governance, which further increases growth. As a result, institutional quality has a double dividend, which suggests considerable benefits to educational reforms.

\section{Keywords}

Institutions, Human Capital, Education, Growth

\section{Introduction}

The literature on the quantifiable measurement of educational return or performance at the microeconomic level has been developed considerably. This development is consistent with the growing availability of socio eco-

${ }^{*}$ Corresponding author. 
nomic data. This literature has been centered on the utility function or the Jacob Mincer equation.

In accordance with this fundamental equation, the salary of a representative individual is presented as a function of the number of his/her education years: period spent at school. Thus, this feature enables the measurability of an extra year of study by its marginal effect on the utility function. Accordingly, the decision to extend the number of schooling years results from an arbitrage in which at equilibrium, every individual is indifferent in the choice between two potential options: the option to continue his/her studies or the option to immediately enter the labour market. This choice is influenced by the teachings of the human capital theory, developed by [1].

In essence, according to this theory, the decision by economic agents to unfold their educational careers depends on: a comparison between benefits in terms of growth in salaries once they integrate the labour market and the opportunity cost in terms of revenue lost if they should decide to pursue an additional year of education. The return of education is explained in the human capital theory by a fundamental hypothesis: passage through the curriculum tends to increase productivity and therefore the income of individuals.

The main predictions of this theory on the effectiveness of the educational system are based on two fundamental assumptions. The first is based on the assumption of marginal returns of production factors. Under perfect competition, the salary of an individual is determined by marginal productivity. The second hypothesis is based on the direct link between the effective productivity of individuals and the knowledge acquired during an educational career. In the theory of human capital, the educational system enables the acquisition of productive skills. Certainly one of the main functions of education is the transmission of knowledge that is intended to facilitate the adaptation of societies to economic changes.

However, an alternative theory called the "signal of filter" theory by [2] has interpreted the positive correlation between education and salaries. In this theory, the main function of the school is not to train but to classify and select individuals. According to this paradigm, school or education provides no real skills to individuals, but simply selects and reveals those skills (individuals) that are most suitable at the outset. Accordingly, in a context of uncertainty or asymmetric information on the effective productive skills of individuals, education has an informative role in providing the labor market an effective means of selecting employees because recruitment is most often characterized by uncertainty. With respect to this theory, education does not produce but identify qualities that are valorized by the entrepreneurial sector. Hence, the length of schooling and the quality of training will remain important signals enabling the identification of good candidates, even if the content of the training matters less. This is why instead of validating the knowledge transmitted and acquired, the education of individuals works more like a signal. According to this theory, education has an essential function of serving as a filter in revealing to the society talents of individuals that are most qualified ex-ante. It seems obvious to us that the theory of [2] is analogous to the biological theory of the principle of disability by [3].

If it is difficult to decide between the human capital theory and the theory of signal, at the empirical level they are not really different at the level of demand for education. According to the theoretical predictions of the two competing theories in the socio-economic system, individuals are naturally motivated to seek further education in order to obtain a higher salary, irrespective of the type of education functions: training and selection. Indeed, school education currently occupies an increasing role in the social life of developed countries as well as developing countries, as evidenced by improvements in the average years of schooling and the role of qualifications in facilitating integration into the labor market.

Finally, regardless of the theoretical framework, it should be noted that the measurement of private school return by the number schooling years is too simplistic. Indeed, the recent literature seems to ignore the role of social interactions and externalities associated with them in the formation of human capital. These externalities exist between individuals or groups of individuals or between successive generations. Similarly, social infrastructure plays a fundamental role in the incentives for human capital accumulation [4].

The impact of this set of educational externalities is deduced from the analysis of the educational performance at the macroeconomic level.

A seminal analysis of the macroeconomic impact of education on growth has been provided by neo-classical growth models ([5] [6]). These authors have shown empirically from cross-sectional data that, human capital proxied by the rate of scholarly enrollment practically plays the same role in the production function as physical capital. Consequently, the extension of schooling years tends to increase the productive efficiency of the labor force. Thus, increasing the induced productivity tends to offset the effects of diminishing returns to capital and hence, the long term growth. As a corollary, the implementation of sustained economic growth requires an increase in the educational level of the population in countries. The macroeconomic outcome validates at the 
global level those from the microeconomic predictions.

However, the main results of Mankiw, Romer and Weil, were seriously challenged by [7] and [8]. These authors, not only sustain by their empirical analysis that there is no effect of human capital on the income of nations, but also show that sometimes the level of human capital has a negative impact on income. However, their negative results were also questioned by [9] who were able to empirically validate the positive impact of human capital on economic growth. A study by [7] had raised great doubts on the basic main micro econometric result of the positive correlation between education and income.

Indeed, in order to reconcile the robustness of this result at the macroeconomic level, it is relevant to take into account the presence and quality of the externality of social infrastructure ([4]). Since the seminal paper of [10] on the crucial role of the quality of institutions and the economic development of nations, a new literature on the quality of governance institutions and the performance of nations has emerged. Accordingly, given the substantial educational policy reforms in the world, it is worthwhile to theoretically analyze at a macroeconomic level, the main mechanisms through which the positive impact of education on growth (and economic development) occurs. One of the main channels through which the effect of human capital passes is the productivity of the educational sector. The quality of this sector varies with countries, the level of endemic corruption and incentives involved ([11]-[13]).

Our theoretical paper attempts to reconcile the above stylized facts on the nexus between education and growth by formally investigating the relationship between the quality of governance, education and growth. We will show the horizon of educational dividends when the establishment of good governance is taken into account.

The rest of the paper is organized as follows. Section 2 presents the characteristics of a simple model. The characterization of equilibrium growth is covered in Section 3. Section 4 concludes.

\section{A Simple Model and Results}

Let us consider a simple model describing a small open economy within the framework of nested generation. The two-period model examines the behavior of two generations: young and old. In each period, individuals are endowed with one unit of working time (we do not consider leisure time for simplicity). Young people either have the choice between working in the first period for income generation or study to improve their human capital which is inherited from the generation of their parents. Indeed, it is assumed that education generates a positive externality from one generation to another ([14]).

The income generated is spent on consumption and savings. It is assumed that the old cannot devote their time to studies: they only work and eat without leaving debts. The wealth of the economy depends on the overall level of savings. This wealth consists of the stock of physical capital which is used with labor and the stock of knowledge or technology by the competitive sector of national firms.

This simple analytical framework enables the characterization of incentives for education undertaken by young agents, as well as national aggregate output. Finally, we assume that the population size of all is unitary.

\subsection{Behavior of Individuals}

An individual born in period $t$ is assumed to maximize the following inter temporal utility function:

$$
U_{t}=u\left(c_{t}^{1}\right)+\frac{1}{1+\rho} u\left(c_{t}^{2}\right)
$$

where: $u^{\prime}()>$.0 and $u^{\prime \prime}()<$.0 are the standard hypotheses and $\rho$ is the temporal discount rate.

Utility is defined as the amount of consumption of the first and second periods $c_{t}=\left(c_{t}^{1}, c_{t}^{2}\right)$, where $t$ is the index denoting the birth period of the youths. Individuals maximize their given inter-temporal utility function (Equation (1)), under the following budgetary constraints:

$$
\begin{gathered}
c_{t}^{1}+s_{t}^{1}=\omega_{t}\left(1-e_{t}\right) h_{t}^{1} \\
c_{t}^{2}=\omega_{t+1} h_{t}^{2}+s_{t}^{1}\left(1+r_{t+1}\right)
\end{gathered}
$$

and

$$
h_{t}^{2}=\left(1+f\left(S, e_{t}\right)-\delta\right) h_{t}^{1}
$$


with:

$\omega=\left(\omega_{t}, \omega_{t+1}\right)$ is the vector of real salaries by unit of effective time in the periods $t$ and $t+1, r_{t+1}$ is global interest rate for saving collected in period $t$ with the supposition that the financial market is efficient; and $h_{t}^{1}$ is the level of human capital inherited from the old generation, such as the preceding generation, which reveals an inter-generational externality.

In the first period, the youths are presumed to allocate a portion of their time (unity) to education of quantity (number of years) $e_{t}$ which induces a rate of academic return $f(S, e)$ depending on the quality of governance of the national education system.

A direct extension of this representation is to assume that in a game of social interaction, the performance also depends on the externality from the average general educational level ([15]).

The term corporate governance includes, among others, the prevalence of corruption, quality and teachers' civics, and the quality of educational infrastructure. The quality of governance is given by a scale parameter $S$, denoting the index of institutional quality with the following assumptions:

$$
f(S, 0)=0 ; \frac{\partial f}{\partial e}(S, e)>0 ; \frac{\partial^{2} f}{\partial e^{2}}(S, e)<0 ; \frac{\partial^{2} f}{\partial S \partial e}(S, e)>0 .
$$

And the institutional quality of the educational system is assumed to be complementary in terms of performance relative to the number schooling years. It is also assumed that human capital depreciates per unit time at a given constant rate $\delta$.

Taking into account these assumptions and constraints, the inter-temporal utility optimization program of a representative individual becomes:

$$
\max _{S, e} U_{t}=u\left(\omega_{t}\left(1-e_{t}\right) h_{t}^{1}-s_{t}^{1}\right)+\frac{1}{1+\rho} u\left(\omega_{t+1}\left(1+f\left(S, e_{t}\right)-\delta\right) h_{t}^{1}+s_{t}^{1}\left(1+r_{t+1}\right)\right)
$$

The equilibrium conditions of the first order are as follows:

$$
\begin{gathered}
u^{\prime}\left(c_{t}^{1}\right)=\frac{1}{1+\rho}\left(1+r_{t+1}\right) u^{\prime}\left(c_{t}^{2}\right) \\
\omega_{t} h_{t}^{1} u^{\prime}\left(c_{1}^{t}\right)=\frac{\omega_{t+1}}{1+\rho} \frac{\partial f}{\partial e_{t}}\left(S, e_{t}\right) h_{t}^{1} u^{\prime}\left(c_{t}^{2}\right) .
\end{gathered}
$$

The interpretation of these results is straightforward and intuitively easy. The equilibrium condition in Equation (7) tells us that the optimal savings is given by the equality between the marginal utility of consumption when young, with the expected marginal utility at old age. Then, the condition characterizing the optimal length of schooling is given by the equality between the marginal cost in terms of consumption utility in the first period with the expected gain of the marginal utility of consumption allowed by the extension of human capital, as well as its rate of return. In addition, we note that the optimal duration of schooling is independent of the discount rate, as well as individual preferences.

\section{Proposition 1}

The optimal duration of schooling is based on social mobility and the financial opportunity cost and is given by the following equation:

$$
\frac{\partial f}{\partial e_{t}}\left(S, \hat{e}_{t}\right)=\left(1+r_{t+1}\right) \frac{\omega_{t}}{\omega_{t+1}}=\frac{\left(1+r_{t+1}\right)}{\frac{\omega_{t+1}}{\omega_{t}}}
$$

\section{Proof:}

The result is obtained by a simple substitution game of Equations (7) and (8).

Let us take $\frac{\omega_{t+1}}{\omega_{t}}=1+g_{t}$, where $g_{t}$ is the rate of expected wage growth and assuming no uncertainty, we obtain:

$$
\frac{\partial f}{\partial e_{t}}\left(S, \hat{e}_{t}\right)=\frac{\left(1+r_{t+1}\right)}{\left(1+g_{t}\right)}
$$


Consequently, this simple rewrite tells us that the optimal duration of education is done by the usual trade-off between financial performance and the returns to human capital given by the rate of wage growth. This result highlights the role of education in the quest for upward social mobility and pending emergence of the middle class (like in Arab countries).

\section{Corollary 1}

We have results from the following comparative statics:

$$
\frac{\partial \hat{e}_{t}}{\partial S}(.)>0 ; \frac{\partial \hat{e}_{t}}{\partial r_{t+1}}(.)<0 ; \frac{\partial \hat{e}_{t}}{\partial\left(\frac{\omega_{t+1}}{\omega_{t}}\right)}(.)>0 .
$$

Proof:

From Equation (9) we obtain by simple representation:

$$
\frac{\partial^{2} f}{\partial e \partial S} \mathrm{~d} S+\frac{\partial^{2} f}{\partial\left(e_{t}\right)^{2}} \mathrm{~d} e_{t}=0 \Rightarrow \frac{\mathrm{d} e_{t}}{\mathrm{~d} S}=-\frac{\frac{\partial^{2} f}{\partial e \partial S}}{\frac{\partial^{2} f}{\partial\left(e_{t}\right)^{2}}}>0 .
$$

And

$$
\frac{\partial^{2} f}{\partial\left(e_{t}\right)^{2}} \frac{\mathrm{d} e_{t}}{\mathrm{~d} r_{t+1}}=\frac{\omega_{t}}{\omega_{t+1}} \Rightarrow \frac{\mathrm{d} e_{t}}{\mathrm{~d} r_{t+1}}=\frac{\frac{\omega_{t}}{\omega_{t+1}}}{\frac{\partial^{2} f}{\partial\left(e_{t}\right)^{2}}}<0
$$

Also:

$$
\frac{\partial^{2} f}{\partial\left(e_{t}\right)^{2}} \frac{\mathrm{d} e_{t}}{\mathrm{~d}\left(\frac{\omega_{t+1}}{\omega_{t}}\right)}=-\frac{1+r_{t+1}}{\left(\frac{\omega_{t+1}}{\omega_{t}}\right)^{2}} \Rightarrow \frac{\mathrm{d} e_{t}}{\mathrm{~d}\left(\frac{\omega_{t+1}}{\omega_{t}}\right)}=-\frac{1+r_{t+1}}{\left(\frac{\omega_{t+1}}{\omega_{t}}\right)^{2} \frac{\partial^{2} f}{\partial\left(e_{t}\right)^{2}}}>0
$$

These results seem to be very important because they provide us with the conditions that drive the accumulation of human capital, the length of schooling and the training of an effective productive workforce. Indeed, the first result tells us that the institutional quality of the educational or school system $S$ is fundamental as a variable. The variable can be approximated by the rate of supervision of countries like Morocco.

Then the second result tells us that an efficient financial system seems to be a substitutable element to the rate of return on human capital in order to ensure consumer spending in the second period (although it is necessary to extend the discussion on the equality of rates as a puzzle).

Finally, the last result is directly related to the given upward social mobility or interpreted here as the rate of wage growth (to be linked with empirical studies as well as the technological diffusion rate).

\subsection{Entrepreneurs and Economic Growth}

Firms are expected to operate competitively in the goods as well as in the input markets. They are identical and maximize their profits. The national aggregate output is given by a production function in constant returns to scale with respect to aggregate physical capital $K$ and the actual total amount of work $H$ :

$$
Y_{t}=A_{t} F\left(K_{t}, H_{t}\right)
$$

where:

$$
H_{t}=\left(1-e_{t}\right) h_{t}^{1}+h_{t}^{1}=\left(2-e_{t}\right) h_{t}^{1}
$$

and where $A(t)$ denotes the stock of existing technology or the state of knowledge or social infrastructure of the country under consideration.

Given the assumption of constant returns, the output per unit of effective labor is given by: 


$$
Y_{t}=A_{t} f\left(k_{t}\right)\left(2-e_{t}\right) h_{t}^{1} \Rightarrow y_{t}=\frac{Y_{t}}{H_{t}}=A_{t} f\left(k_{t}\right)
$$

where: $k_{t}=\frac{K_{t}}{H_{t}}$ is physical capital per unit of efficient or effective labor.

The competitive behavior of firms leads to the following first order equilibrium conditions:

$$
\begin{gathered}
r_{t}=A_{t} f^{\prime}\left(k_{t}\right)-\delta=A_{t} F_{K}^{\prime}\left(K_{t}, H_{t}\right)-\delta \\
\omega_{t}=A_{t}\left(f\left(k_{t}\right)-k_{t} f^{\prime}\left(k_{t}\right)\right)=A_{t} F_{H}^{\prime}\left(K_{t}, H_{t}\right) .
\end{gathered}
$$

Here it is assumed that physical capital $K$ depreciates at the same rate as human capital and where the interest rate is given for firms choosing their optimal equipment. And physical capital is an increasing function of the increase in total factor productivity $A(t)$, and the quality of the actual human capital stock.

At a steady state $A, r, e$, and $f(k)$ are constant and thus the growth rate of the economy is given by:

$$
\frac{Y_{t}}{Y_{t-1}}=\left(1+\phi\left(S, e_{t}\right)-\delta\right)=1+\hat{g}
$$

\section{Proposition 2}

Institutional governance generates a Double Dividend, since the economic growth rate increasingly depends on the schooling rate as well as the quality of the educational system:

$$
\hat{g}=\phi\left(S, e_{t}\right)-\delta .
$$

\section{Proof:}

It is evident and omitted.

This result is very relevant to us. Indeed, the index of the quality of corporate governance given by the S parameter seems to play-out (by means of two main channels) a fundamental role on the rate of growth (directly or indirectly based on incentives). Accordingly, we respect to the first or direct channel, good corporate governance tends to encourage individuals to invest in long lengths of study which involves strong human capital accumulation and directly affects the growth rate. Moreover, as the economic growth rate depends on the rate of return on human capital, good governance institutions also impact this performance and therefore translate this impact on the growth rate of the economy. Accordingly, the second channel appears in the explicit function of the economic growth rate.

It is easy to empirically show that the duration of studies are increasing functions of the quality of institutions in countries ([16]). Similarly lengthy schooling years directly and positively affect research \& development (R $\& \mathrm{D})$ and therefore the growth in advanced countries by means technical progress.

\section{Conclusions}

This study has articulated the interaction among institutional governance, education and economic growth. Given the current pursuit of education policy reforms and knowledge economy around the world, it is of policy relevance to theoretically analyze the main mechanisms by which the macroeconomic impact of education on growth (and economic development) occurs. Our theoretical model demonstrates how incentives offered by the government affect human capital accumulation which ultimately engenders positive economic development externalities. We articulate two main channels through which education affects economic growth. The first channel highlights direct positive effect of educational quality on the incentive to accumulate human capital by individuals, which makes them more productive. The second channel appears in the explicit function of the economic growth rate. As a policy implication, we have shown that the growth rate depends on the rate of return on human capital or that this rate of return itself depends on the quality of governance, which further increases growth. As a result, institutional quality has a double dividend, which suggests considerable benefits to educational reforms (e.g. in a country like Morocco).

Future studies devoted to improving the extant literature can focus on investigating if the established theoretically linkages withstand empirical validity. 


\section{Acknowledgements}

The authors thank an anonymous referee.

\section{References}

[1] Becker, G. (1964) Human Capital: A Theoretical and Empirical Analysis, with Special Reference to Education. Columbia University Press, New York.

[2] Spence, M. (1973) Job Market Signalling. Quarterly Journal of Economics, 87, 355-373. http://dx.doi.org/10.2307/1882010

[3] Zahavi, A. (1975) Mate Selection-Selection for a Handicap. Journal of Theoretical Biology, 53, $205-214$. http://dx.doi.org/10.1016/0022-5193(75)90111-3

[4] Hall, R.E. and Jones, Ch.I. (1999) Why Do Some Countries Produce So Much More Output per Worker than Others? Quarterly Journal of Economics, 114, 83-116. http://dx.doi.org/10.1162/003355399555954

[5] Solow, R.M. (1956) A Contribution to the Theory of Economic Growth. The Quarterly Journal of Economics, 70, 6594. http://dx.doi.org/10.2307/1884513

[6] Mankiw, N.G., Romer, D. and Weil, D.N. (1992) A Contribution to the Empirics of Economic Growth. Quarterly Journal of Economics, 107, 407-437. http://dx.doi.org/10.2307/2118477

[7] Benhabib, J. and Spiegel, M.M. (1994) The Role of Human Capital in Economic Development: Evidence from Aggregate Cross-Country Data. Journal of Monetary Economics, 34, 143-173. http://dx.doi.org/10.1016/0304-3932(94)90047-7

[8] Pritchett, L.H. (2001) Where Has All the Education Gone? World Bank Economic Review, 15, 367-391. http://dx.doi.org/10.1093/wber/15.3.367

[9] Krueger, A.B. and Lindahl, M. (2001) Education for Growth: Why and For Whom? Journal of Economic Literature, 39, 1101-1136. http://dx.doi.org/10.1257/jel.39.4.1101

[10] Acemoglu, K.D., Johnson, S. and Robinson, J.A. (2005) Institutions as a Fundamental Cause of Long-Run Economic Growth. In: Aghion, Ph. and Durlauf, S.N., Eds., Handbook of Economic Growth, Volume 1 of Handbooks in Economics, Chapter 6, Elsevier, Amsterdam, 385-472.

[11] Reinikka, R. and Svensson, J. (2005) Fighting Corruption to Improve Schooling: Evidence from a Newspaper Campaign in Uganda. Journal of the European Economic Association, 3, 259-267. http://dx.doi.org/10.1162/1542476054472883

[12] Rogers, M.L. (2008) Directly Unproductive Schooling: How Country Characteristics Affect the Impact of Schooling on Growth. European Economic Review, 52, 356-385. http://dx.doi.org/10.1016/j.euroecorev.2007.03.001

[13] Gupta, S., Davoodi, H.R. and Tiongson, E.R. (2001) Corruption and the Provision of Health Care and Education Services. In: Jain, A.K., Ed., The Political Economy of Corruption, Chapter 6, Routledge, London, 111-141.

[14] Azariadis, C. and Drazen, A. (1990) Thresholds in Economic Development. Quarterly Journal of Economics, 105, 501-526. http://dx.doi.org/10.2307/2937797

[15] Jellal, M. and Bouzahzah, M. (2012) Cultural Beliefs, Education and Growth. MPRA Paper No. 38763.

[16] Jellal, M. (2012) Education, Institutions et Culture, Mimeo. 